\title{
ON THE STABILITY OF FRAME MEMBERS IN A GLOBAL BUCKLING*
}

\author{
Fumio NISHINO ${ }^{1}$, Masahiro $\mathrm{AI}^{2}$ and Tomofumi NAKANO ${ }^{3}$ \\ ${ }^{1}$ Mem. of JSCE, Ph.D., Prof., Grad. School of Policy Science, Saitama Univ. \\ (Urawa Saitama 338, Japan) \\ ${ }^{2}$ Mem. of JSCE, Dr.Eng., Prof., Dept. of Civil Engng., Hosei Univ. \\ (Koganei Tokyo 184, Japan) \\ ${ }^{3}$ Mem. of JSCE, M.Eng., Japan Bridge Co. (Fukuzaki Minato-ku Osaka 552, Japan)
}

\begin{abstract}
In the global buckling of a framed structure, members are examined for their own stabilities. It is shown that, besides the actual member forces exerted, there can be considered a critical axial force of each member determined by its displacement mode in the global buckling. The effective lengths of members are defined for those critical forces. The stability state of each member is qualified by the actual axial force acting on that effective length. The global buckling is explained as an assembly of those stability states of members.
\end{abstract}

Key Words : frame structure, effective length, member stability, buckling

\section{INTRODUCTION}

While the recent computer analysis can easily determine the global buckling of a framed structure, in the stability design, the axial strength of members has been dealt with by the concept of effective length. This is supposed because of its practical usefulness in the design procedure. At the same time, the difficulty is how the actual effective lengths are evaluated appropriately. The specified lengths in the existing design codes e.g.1) are restricted to a truss or a rectangular rigid frame. Further, they can have excessive margins.

In those circumstances, there has been presented one method for a general framework ${ }^{2)}$, in which, after the eigenvalue analysis of a global buckling, by an inverted use of the Eulerbuckling formula, the effective lengths for compressed members are individually estimted from their axial forces. In view of its practical usage, that method suggests a desirable way in the computational analyses. However, after examined in the usual structures in various load-

\footnotetext{
* A main part of this paper has been presented at the JSCE Annual Conference ${ }^{9}$ ), held in Nagoya, 1996-9.
}

ings, certain shortages have been revealed: as reported previously ${ }^{3-6}$ ), the effective length for a slightly compressed member becomes extremely large; and the opposite evaluation is given for the changes of cross-section in members.

Some improvements have been suggested for that method: for instance, in one treatment ${ }^{5}$, the small compressive member forces existing in a global buckling are amplified to correct their effective lengths; and, in another one ${ }^{7)}$, instead of the member forces exerted in the loading, the axial strength forces estimated conventionally from the member cross-sections are adopted in the eigenvalue problem.

In this study, the behaviors of members in a global buckling are analyzed within the stability theory of a discretized structure. As a result, the compressed members are not necessarily in their own critical states. Besides the actual member forces exerted in the loading, there can be considered another critical axial force for each member, which is derived from its displacement mode in the global buckling. The effective member length is defined for that critical force. Then, the stabil- 
ity state of each member is qualified by the actual axial force acting upon that effective length. It is shown that the global buckling is a result of those member stability states coupled.

\section{GLOBAL BUCKLING}

We consider a linear loading applied to the initial state of a framed structure:

$$
\left\{P_{N}\right\}=\rho\left\{P_{N}^{*}\right\}
$$

where $\left\{P_{N}^{*}\right\}$ is a mode of loading; and $\rho$ is the load factor. While the members are subject to certain axial forces, for a simplified expansion, their bending deformations are here assumed to be small enough up to the buckling. In those small displacements, the buckling mode, $\left\{X_{N}^{S}\right\}$, and the magnitude of load, $\rho^{S}$, can be determined by the well-known eigenvalue problem:

$$
\left(\left[K_{O N}\right]+\rho^{S}\left[K_{G N}^{*}\right]\right)\left\{X_{N}^{S}\right\}=\{0\}
$$

where $\left[K_{O N}\right]$ is the initial stiffness matrix; and $\left[K_{G N}^{*}\right]$ denotes the geometrical stiffness matrix exerted by the axial member forces, per unit of loading factor $\rho$.

In the potential theory of buckling: For an infinitesimal displacement $\delta\left\{u_{N}\right\}$ from an equilibrium state, since the nodal forces $\left\{F_{N}\right\}$ exerted in members have been equal to the external $\left\{P_{N}\right\}$, the first variation of total potential energy $W$ results into zero. By the use of tangent stiffness $\left[K_{N}(\rho)\right]=\left[K_{O N}\right]+\rho\left[K_{G N}^{*}\right]$, the second variation is written as

$$
\delta^{2} W=\frac{1}{2} \delta\left\{u_{N}\right\}^{T}\left[K_{N}(\rho)\right] \delta\left\{u_{N}\right\}
$$

This quadratic form is positive definite in the stable domain lying around the initial state. The buckling state on the load path (1) is equivalent to a point where the quadratic form turns into semi-positive definite:

$$
(\Gamma=)\left\{X_{N}^{S}\right\}^{T}\left[K_{N}\left(\rho^{S}\right)\right]\left\{X_{N}^{S}\right\}=0
$$

\section{STABILITY OF MEMBERS}

Stiffness matrix $\left[K_{N}\right]$ of a framed structure is derived by the superposition of member stiffness matrices $[k]_{(m)}$, in the entire nodal freedom. Then, by collecting each member's mode $\{\boldsymbol{X}\}_{(m)}$ from the global $\left\{X_{N}^{S}\right\}$, we can rewrite quadratic form (4) into the sum of the members' works:

$$
\begin{aligned}
& \Gamma=\sum_{m=1}^{M} I_{(m)} \\
& I_{(m)}=\left\{X^{S}\right\}_{(m)}^{T}\left[k\left(\rho^{S}\right)\right]_{(m)}\left\{X^{S}\right\}_{(m)}
\end{aligned}
$$

When the structure attains to a neutral stiffness in mode $\left\{X_{N}^{S}\right\}$, the sum becomes zero. But, this zero value usually consists of positive and negative $I_{(m)}$ of members. Concerning the stability of each member in the global buckling, the followings can be said:

$I_{(m)}>0:$ member $(\mathrm{m})$ is stable into its nodal displacement $\left\{X^{S}\right\}_{(m)}$, acting to restrain the global buckling $\left\{X_{N}^{S}\right\}$ by its positive stiffness.

$I_{(m)}<0:(\mathrm{m})$ is instable into $\left\{\boldsymbol{X}^{S}\right\}_{(m)}$, pushing forward the buckling $\left\{X_{N}^{S}\right\}$ by its negative stiffness.

\section{EFFECTIVE MEMBER LENGTH IN MODE $\left\{\boldsymbol{X}^{S}\right\}_{(m)}$}

Let the axial forces of members at the global buckling be denoted by $N_{(m)}^{S}$. As stated before, the members with $N \underset{(m)}{S}$ exist in the structure to be stable or instable. Now, we can consider another axial force $N_{(m)}^{C}$ for which member $(\mathrm{m})$ is critical into its mode $\left\{\boldsymbol{X}^{S}\right\}_{(m)}$ :

$$
\left\{\boldsymbol{X}^{S}\right\}_{(m)}^{T}\left(\left[k_{O}\right]+N^{C}\left[\bar{k}_{G}\right]\right)_{(m)}\left\{X^{S}\right\}_{(m)}=0
$$

where $\left[k_{O}\right]_{(m)}$ is the initial stiffness of member $(\mathrm{m})$; and $\left[\bar{k}_{G}\right]_{(m)}$ is the geometrical stiffness per unit axial compression. Since $\left\{\boldsymbol{X}^{S}\right\}_{(m)}$ have been obtained in the global-buckling analysis, we have

$$
N_{(m)}^{C}=-\frac{\left\{X^{S}\right\}_{(m)}^{T}\left[k_{O}\right]_{(m)}\left\{X^{S}\right\}_{(m)}}{\left\{X^{S}\right\}_{(m)}^{T}\left[\bar{k}_{G}\right]_{(m)}\left\{X^{S}\right\}_{(m)}}
$$

The actual $N_{(m)}^{S}$ are now compared with those $N_{(m)}^{C}$ : in place of the former discriminant $I_{(m)}>0$ and $I_{(m)}<0$, the same sayings hold for $N_{(m)}^{S}<$ $N_{(m)}^{C}$ and $N_{(m)}^{S}>N_{(m)}^{C}$, respectively. 
In the mode $\left\{\boldsymbol{X}^{S}\right\}_{(m)}$ imposed by the global buckling, $N_{(m)}^{C}$ is the buckling force for each member. Thus, the effective length of member $(\mathrm{m})$ is now estimated for $N_{(m)}^{C}$, rather than for $N_{(m)}^{S}$ :

$$
l_{\text {eff. }(m)}^{C}=\pi \sqrt{\frac{E I}{N_{(m)}^{C}}}
$$

where $E$ is the Young's modulus; and $I$ is the moment of inertia of cross-section. When the actual axial-stress ratios are plotted on those slenderness parameters, as shown in Fig.1, the members are divided by the Euler curve into three groups: tensioned; compressed less than instability; and compressed into instability.

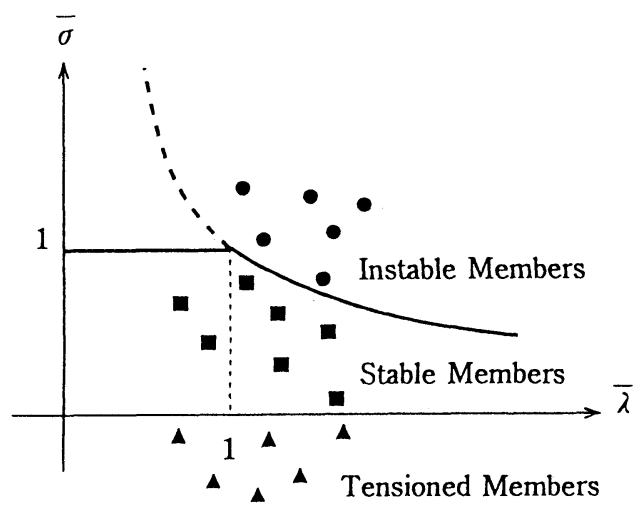

Fig. 1 Stability state of members

\section{EFFECTIVE MEMBER LENGTH IN DEFORMATION MODE}

The quadratic work of each member, $I_{(m)}$, is significant in the global buckling. However, this quantity does not determine the member's own stability strength. For instance, suppose a framework containing some rigid members. The rotation as a rigid body of such a member compressed is instable: its $I_{(m)}$ has a negative value. But, we can not suppose the buckling of itself.

A two-dimensional framework is here considered in our actual formulation. Let the nodal displacements and the nodal forces of member $(\mathrm{m})$ be denoted by

$$
\begin{aligned}
\{\boldsymbol{u}\}_{(m)} & =\left\{(u, v, \theta)_{i},(u, v, \theta)_{j}\right\} \\
\{\boldsymbol{F}\}_{(m)} & =\left\{\left(F_{x}, F_{y}, M\right)_{i},\left(F_{x}, F_{y}, M\right)_{j}\right\}
\end{aligned}
$$

respectively. The geometrical stiffness matrix is written as

$$
\left[k_{G}\right]_{(m)}=-N\left[\begin{array}{cccccc}
0 & 0 & 0 & 0 & 0 & 0 \\
& \frac{6}{5 l} & \frac{1}{10} & 0 & \frac{-6}{5 l} & \frac{1}{10} \\
& & \frac{2 l}{15} & 0 & \frac{-1}{10} & \frac{-l}{30} \\
& & & 0 & 0 & 0 \\
& \text { Sym. } & & & \frac{6}{5 l} & \frac{-1}{10} \\
& & & & & \frac{2 l}{15}
\end{array}\right]
$$

where $l$ is the initial member length.

Now, let a simple support be supposed upon member (m) to constran its displacement as a rigid body. By its assistance, as shown in Fig.2, we can separate nodal displacements $\{\boldsymbol{u}\}_{(m)}$ into two parts: displacement of the staticallydeterminate support itself, $\boldsymbol{v}_{(m)}=\left\{u_{i}, v_{i}, \tau\right\}$, and deformation of (m) within that support, $\epsilon_{(m)}=$ $\left\{\Delta, \phi_{A}, \phi_{B}\right\}$. Their geometrical relations are written as

$$
\tau=\frac{v_{j}-v_{i}}{l}
$$

and

$$
\begin{aligned}
& \epsilon_{(m)}=\left[Q_{X}\right]_{(m)}\{u\}_{(m)} \\
& {\left[Q_{X}\right]_{(m)}=\left[\begin{array}{cccccc}
-1 & 0 & 0 & 1 & 0 & 0 \\
0 & \frac{1}{l} & 1 & 0 & \frac{-1}{l} & 0 \\
0 & \frac{1}{l} & 0 & 0 & \frac{-1}{l} & 1
\end{array}\right]}
\end{aligned}
$$

For $\boldsymbol{v}_{(m)}$, apparently, no nodal forces come from the initial stiffness $\left[k_{O}\right]_{(m)}$. But, as a geometrical effect on the preceding $N_{(m)}$, rotation $\tau$ produces spatial components $F_{y i}=-F_{y j}=$ $N_{(m)} \tau$. In terms of $\{\boldsymbol{u}\}_{(m)}$, we have

$$
\begin{gathered}
\{\boldsymbol{F}\}_{(m)}=\left[k_{G}^{R}\right]_{(m)}\{\boldsymbol{u}\}_{(m)} \\
{\left[k_{G}^{R}\right]_{(m)}=-\frac{N}{l}\left[\begin{array}{cccccc}
0 & 0 & 0 & 0 & 0 & 0 \\
& 1 & 0 & 0 & -1 & 0 \\
& & 0 & 0 & 0 & 0 \\
& & & 0 & 0 & 0 \\
& \text { Sym. } & & & 1 & 0 \\
& & & & & 0
\end{array}\right]}
\end{gathered}
$$




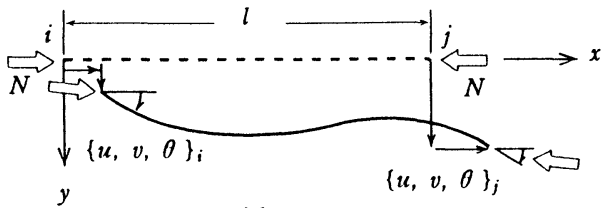

II
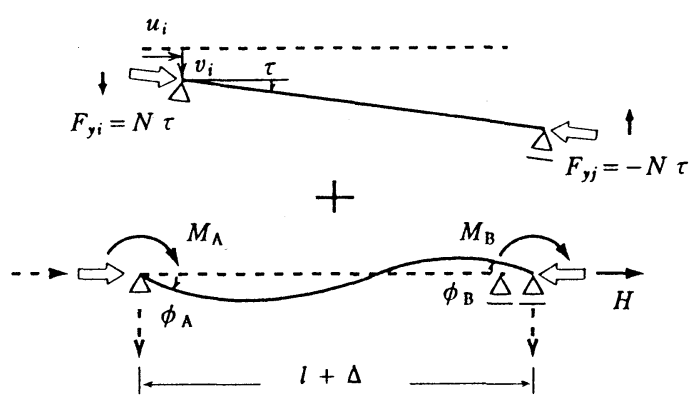

Fig. 2 Deformation and displacement as a rigid body

The stiffness for deformation $\epsilon_{(m)}$ can be dealt with within the simple support fixed in the space. Let force components into $\left\{\Delta, \phi_{A}, \phi_{B}\right\}$ be denoted by $f_{(m)}=\left\{H, M_{A}, M_{B}\right\}$ (see Fig.2). By the linearized discretization of that member subjected to the preceding $N_{(m)}$, we have the following result:

$$
\begin{aligned}
& f_{(m)}=\left(\left[\kappa_{O}\right]+\left[\kappa_{G}\right]\right)_{(m)} \epsilon_{(m)} \\
& {\left[\kappa_{O}\right]_{(m)}=\left[\begin{array}{ccc}
\frac{E A}{l} & 0 & 0 \\
& \frac{4 E I}{l} & \frac{2 E I}{l} \\
\text { Sym. } & & \frac{4 E I}{l}
\end{array}\right]} \\
& {\left[\kappa_{G}\right]_{(m)}=-N l\left[\begin{array}{ccc}
0 & 0 & 0 \\
& \frac{2}{15} & \frac{-1}{30} \\
\text { Sym. } & \frac{2}{15}
\end{array}\right]}
\end{aligned}
$$

where $A$ is the area of cross-section. In those reduced degrees of freedom, $\left[\kappa_{O}\right]_{(m)}$ is the initial stiffness caused by the elastic deformation, and $\left[\kappa_{G}\right]_{(m)}$ is the geometrical stiffness for $N_{(m)}$.

By taking account of the reactive forces for $\left\{H, M_{A}, M_{B}\right\}$ in the simple support, we have the entire nodal forces. By the contragredi- ence with Eq.(12), this relation is written as $\{\boldsymbol{F}\}_{(m)}=\left[Q_{X}\right]_{(m)}^{T} \boldsymbol{f}_{(m)}$. Then, the initial stiffness $\left[k_{O}\right]_{(m)}$ used in Eq.(6) is written as $\left[k_{O}\right]_{(m)}=\left[Q_{X}\right]_{(m)}^{T}\left[\kappa_{O}\right]_{(m)}\left[Q_{X}\right]_{(m)}$. Similarly, the geometrical $\left[\kappa_{G}\right]_{(m)}$ is transformed into the six degrees of freedom:

$$
\begin{aligned}
& {\left[k_{G}^{D}\right]_{(m)}\left(=\left[Q_{X}\right]_{(m)}^{T}\left[\kappa_{G}\right]_{(m)}\left[Q_{X}\right]_{(m)}\right)} \\
& {\left[\begin{array}{cccccc}
0 & 0 & 0 & 0 & 0 & 0 \\
& \frac{1}{5 l} & \frac{1}{10} & 0 & \frac{-1}{5 l} & \frac{1}{10} \\
& & \frac{2 l}{15} & 0 & \frac{-1}{10} & \frac{-l}{30} \\
& & & 0 & 0 & 0 \\
& \text { Sym. } & & & \frac{1}{5 l} & \frac{-1}{10} \\
& & & & & \frac{2 l}{15}
\end{array}\right]}
\end{aligned}
$$

This $\left[k_{G}^{D}\right]_{(m)}$ represents the geometrical stiffness for deformation $\epsilon_{(m)}$ contained in nodal displacements $\{\boldsymbol{u}\}_{(m)} \cdot\left\{k_{G}\right]_{(m)}$ given by Eq.(10) is written as the sum of this $\left[k_{G}^{D}\right]_{(m)}$ and the former $\left[k_{G}^{R}\right]_{(m)}$ of Eq.(13·b).

As its own stability strength, we can consider the buckling of member $(\mathrm{m})$ within that simple support (see Fig.3). For its displacement mode $\left\{\boldsymbol{X}^{S}\right\}_{(m)}$, the deformation mode $\boldsymbol{E}_{(m)}^{S}$ is given similarly to Eq.(12). The critical force, say $N_{(m)}^{D}$, is determined for this $\underset{(m)}{S}$. By the use of the former relations, the buckling equation is eventually written as

$$
\left\{X^{S}\right\}_{(m)}^{T}\left(\left[k_{O}\right]+N^{D}\left[\bar{k}_{G}^{D}\right]\right)_{(m)}\left\{X^{S}\right\}_{(m)}=0
$$

Except that $\left[\bar{k}_{G}^{D}\right]_{(m)}$ is placed for $\left[\bar{k}_{G}\right]_{(m)}$, this equation is similar to Eq.(6). Another effective length $l_{\text {eff. }(m)}^{D}$ is estimated for this $N_{(m)}^{D}$. In the plot of this $l_{\text {eff. }(m)}^{D}$ versus the actual $N_{(m)}^{S}$, we can see the stability of members in their deformation modes. Similarly to the former case of $N_{(m)}^{C}$, the members are classified into the three groups. But, since the quadratic work of $\left[k_{G}^{R}\right]_{(m)}$ is not positive for $N_{(m)}>0$, the compressed members are shifted to more stable points: $l_{\text {eff.(m) }}^{D} \leq l_{\text {eff. }(m)}^{C}$.

\section{NUMERICAL ANALYSIS}

So far, for simplicity, our analysis has been based on the stiffness relations linearized upon an 


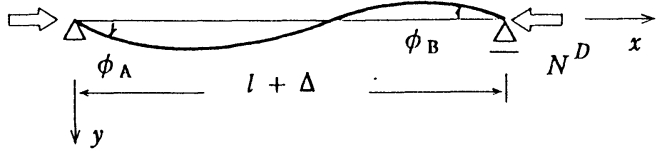

Fig. 3 Member buckling in deformation mode

axially compressed state. Unless each one member is divided into several segments, this analysis contains a certain error: if a simple beam is treated in one segment, for instance, the buckling axial force has an error of about $22 \%$.

To have a good accuracy in the one-to-one segmentation, we here employ a discretization of the 2-D beam for finite displacements developed in Ref.[8]. In that study, after an exact separation of nodal displacements of a beam element into its displacement as a rigid body and its deformation, the stiffness relations are developed by the perturbation method up to the third order of deformation parameters. A numerical comparison is also presented there between the second- and the third-order solutions: the error for the aforesaid simple beam is reduced to $4 \%$. By a pursuit of the nonlinear equilibrium path, not by the eigenvalue problem, the global buckling is determined as a singular state of the tangent stiffness. Together with the treatment developed in the below, if necessary, the procedure is capable to deal with the global buckling after finite displacements.

To derive the critical $N_{(m)}^{C}$ and $N_{(m)}^{D}$ for each member, let some relations be summarized from that discretization, in contrast with the former linearized ones. With $\epsilon_{(m)}$ and $f_{(m)}$ defined by $\left\{\epsilon, \phi_{A}, \phi_{B}\right\}(\epsilon=\Delta / l)$ and $\left\{H l, M_{A}, M_{B}\right\}$, respectively, their tangent stiffness matrix $\left(\delta f_{(m)}=\right.$ $\left.[\kappa]_{(m)} \delta \epsilon_{(m)}\right)$ is written as follows:

$$
\begin{aligned}
& {\left[\kappa\left(H l, \phi_{A}, \phi_{B}\right)\right]_{(m)}=} \\
& {\left[\begin{array}{ccc}
\frac{1}{\gamma_{\epsilon}^{H l}} & \frac{\gamma_{\epsilon}^{\phi A}}{\gamma_{\epsilon}^{H l}} & \frac{\gamma_{\epsilon}^{\phi B}}{\gamma_{\epsilon}^{H l}} \\
& \gamma_{M A}^{\phi A}+\frac{\gamma_{M A}^{H l} \gamma_{\epsilon}^{\phi A}}{\gamma_{\epsilon}^{H l}} & \gamma_{M A}^{\phi B}+\frac{\gamma_{M A}^{H l} \gamma_{\epsilon}^{\phi B}}{\gamma_{\epsilon}^{H l}} \\
\text { Sym. } & & \gamma_{M B}^{\phi B}+\frac{\gamma_{M B}^{H l} \gamma_{\epsilon}^{\phi B}}{\gamma_{\epsilon}^{H l}}
\end{array}\right]}
\end{aligned}
$$

where

$$
\begin{aligned}
\gamma_{\epsilon}^{H l}= & \frac{1}{E A l}+\frac{l}{6300 E I} \cdot \\
& \left(11 \phi_{A}^{2}+11 \phi_{B}^{2}-13 \phi_{A} \phi_{B}\right) \\
\gamma_{\epsilon}^{\phi A}= & \gamma_{M A}^{H l}=\frac{1}{30}\left(4 \phi_{A}-\phi_{B}\right) \\
& -\frac{(H l) l}{6300 E I}\left(22 \phi_{A}-13 \phi_{B}\right) \\
\gamma_{\epsilon}^{\phi B}= & \gamma_{M B}^{H l}=\frac{1}{30}\left(-\phi_{A}+4 \phi_{B}\right) \\
& -\frac{(H l) l}{6300 E I}\left(-13 \phi_{A}+22 \phi_{B}\right) \\
\gamma_{M A}^{\phi A}= & \frac{4 E I}{l}+\frac{2}{15}(H l) \\
& -\frac{E I}{35 l}\left(24 \phi_{A}^{2}-4 \phi_{B}^{2}+6 \phi_{A} \phi_{B}\right) \\
& -\frac{11 l}{6300 E I}(H l)^{2} \\
\gamma_{M B}^{\phi B}= & \frac{4 E I}{l}+\frac{2}{15}(H l) \\
& -\frac{E I}{35 l}\left(-4 \phi_{A}^{2}+24 \phi_{B}^{2}+6 \phi_{A} \phi_{B}\right) \\
& -\frac{11 l}{6300 E I}(H l)^{2} \\
\gamma_{M A}^{\phi B}= & \gamma_{M B}^{\phi A}=\frac{2 E I}{l}-\frac{1}{30}(H l) \\
& -\frac{E I}{35 l}\left(3 \phi_{A}^{2}+3 \phi_{B}^{2}-8 \phi_{A} \phi_{B}\right) \\
& +\frac{13 l}{12600 E I}(H l)^{2} \\
&
\end{aligned}
$$

To be noted: In the former linearized theory, the effect of the preceding axial force, $N_{(m)}$, has been taken into account. In the same sense, the present $f_{(m)}$ and $\epsilon_{(m)}$ involved in the above equations are quantities existing up to the buckling. As the increments in a buckling, variations $\left\{\delta \epsilon, \delta \phi_{A}, \delta \phi_{B}\right\}$ and $\left\{\delta(H l), \delta M_{A}, \delta M_{B}\right\}$, etc. corresponds to the former $\left\{\Delta, \phi_{A}, \phi_{B}\right\}$ and $\left\{H, M_{A}, M_{B}\right\}$, etc.

On a state $\{\boldsymbol{x}\}_{(m)}=\left\{(x, y, \theta)_{i},()_{j}\right\}$, the angular position of member $(\mathrm{m})$ is given by

$$
\tau=\arctan \left(\frac{y_{j}-y_{i}}{x_{j}-x_{i}}\right)
$$

For a variation of $\{\boldsymbol{x}\}_{(m)}$, the change of deformation $\epsilon_{(m)}$ is written as

$$
\begin{aligned}
& \delta \epsilon_{(m)}=\left[Q_{X}(\{\boldsymbol{x}\})\right]_{(m)} \delta\{\boldsymbol{x}\}_{(m)} \\
& {\left[Q_{X}\right]_{(m)}=\left[\begin{array}{rrrrrr}
-\frac{c}{l} & -\frac{s}{l} & 0 & \frac{c}{l} & \frac{s}{l} & 0 \\
-\frac{s}{l^{\prime}} & \frac{c}{l^{\prime}} & 1 & \frac{s}{l^{\prime}} & -\frac{c}{l^{\prime}} & 0 \\
-\frac{s}{l^{\prime}} & \frac{c}{l^{\prime}} & 0 & \frac{s}{l^{\prime}} & -\frac{c}{l^{\prime}} & 1
\end{array}\right]}
\end{aligned}
$$


(20.b) In this equation, the variable is $(H l)_{(m)}$ only, and where $c=\cos \tau, s=\sin \tau$, and $l^{\prime}=\sqrt{ }\left\{\left(x_{j}-\right.\right.$ $\left.\left.x_{i}\right)^{2}+\left(y_{j}-y_{i}\right)^{2}\right\}$.

The nodal forces of member $(\mathrm{m})$ into $\{\boldsymbol{x}\}_{(m)^{-}}$ direction are obtained for $\left\{H l, M_{A}, M_{B}\right\}$ by the contragredience: $\{F\}_{(m)}=\left[Q_{X}\right]_{(m)}^{T} f_{(m)}$. By the differentiation, we have

$$
\begin{aligned}
\delta\{\boldsymbol{F}\}_{(m)}=\left(\delta\left[Q_{X}(\{\boldsymbol{x}\})\right]_{(m)}^{T}\right) \boldsymbol{f}_{(m)} \\
+\left[Q_{X}(\{\boldsymbol{x}\})\right]_{(m)}^{T} \delta \boldsymbol{f}_{(m)}
\end{aligned}
$$

The first term, which reflects the effect of rotation as a rigid body and the change of statics on the deformed configuration, is developed into

$$
\begin{aligned}
& \delta\left\{\boldsymbol{F}^{R}\right\}_{(m)}=\left[k_{G}^{R}(f,\{\boldsymbol{x}\})\right]_{(m)} \delta\{\boldsymbol{x}\}_{(m)} \\
& {\left[k_{G}^{R}\right]_{(m)}=\left[\begin{array}{cc}
{\left[k_{g}^{R}\right]} & -\left[k_{g}^{R}\right] \\
\operatorname{Sym} . & {\left[k_{g}^{R}\right]}
\end{array}\right]} \\
& {\left[k_{g}^{R}\right]=\frac{1}{l^{\prime}}\left[\begin{array}{cc}
\frac{(H l)}{l} \sin ^{2} \tau-\frac{M_{A}+M_{B}}{l^{\prime}} \sin 2 \tau \\
\text { Sym. } \\
-\frac{(H l)}{l} \sin \tau \cos \tau+\frac{M_{A}+M_{B}}{l^{\prime}} \cos 2 \tau & 0 \\
\frac{(H l)}{l} \cos ^{2} \tau+\frac{M_{A}+M_{B}}{l^{\prime}} \sin 2 \tau & 0 \\
& 0
\end{array}\right]}
\end{aligned}
$$

By the use of Eqs.(17) and (20), the second term is developed into the tangent deformation stiffness:

$$
\begin{aligned}
\delta\left\{\boldsymbol{F}^{D}\right\}_{(m)} & =\left[k_{M}(H l,\{\boldsymbol{x}\})\right]_{(m)} \delta\{\boldsymbol{x}\}_{(m)}(23 \cdot \mathbf{a}) \\
{\left[k_{M}\right]_{(m)} } & =\left[Q_{X}\right]_{(m)}^{T}[\kappa]_{(m)}\left[Q_{X}\right]_{(m)}(23 \cdot \mathbf{b})
\end{aligned}
$$

This $\left[k_{M}\right]_{(m)}$, in which $(H l)_{(m)}$ is contained in up to its square term, corresponds to the former $\left[k_{O}\right]_{(m)}+\left[k_{G}^{D}\right]_{(m)}$ in the linearized theory.

In the analysis to determine a global buckling, force components $\left\{H l, M_{A}, M_{B}\right\}$ are connected to deformation parameters $\left\{\epsilon, \phi_{A}, \phi_{B}\right\}$ by the stiffness relation. As the result, we have the axial forces of members, $N_{(m)}^{S}=-(H l) \underset{(m)}{S} / l_{(m)}$, and their buckling modes, $\left\{\boldsymbol{X}^{S}\right\}_{(m)}$. Next, by the use of each member's tangent stiffness $[k]_{(m)}=$ $\left[k_{M}\right]_{(m)}+\left[k_{G}^{R}\right]_{(m)}$, the equation to determine the critical $N_{(m)}^{C}$ is written as

$$
\left\{X^{S}\right\}_{(m)}^{T}[k(f,\{x\})]_{(m)}\left\{X^{S}\right\}_{(m)}=0
$$
other quantities such as $M_{A}$ and $M_{B}$ are fixed at the global buckling. It is not necessary for this $(H l)_{(m)}$ to be related to $\left\{\epsilon, \phi_{A}, \phi_{B}\right\}$. By solving this quadratic equation, we have $N_{(m)}^{C}=$ $-(H l)_{(m)} / l_{(m)}$. By the use of the deformation stiffness $\left[k_{M}(H l,\{\boldsymbol{x}\})\right]_{(m)}$, in place of $[k]_{(m)}$, we have the equation for the critical $N_{(m)}^{D}$ in deformation mode.

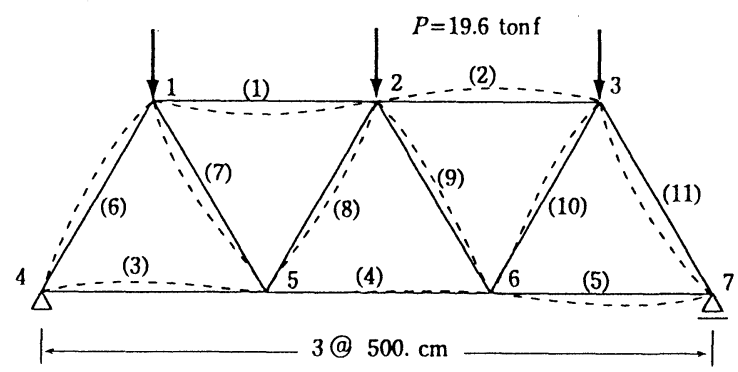

Fig. 4 Buckling mode in Example (1)

Table 1 Actual axial force and critical quantities of members in Example (1)

\begin{tabular}{c|r|rrr} 
No. & \multicolumn{1}{|c|}{$N^{S}$} & $N^{C}$ & $K$ & $\bar{\lambda}$ \\
\hline$(1)$ & 22.78 & 13.61 & 0.959 & 2.18 \\
$(2)$ & 22.53 & 13.88 & 0.950 & 2.15 \\
$(3)$ & -16.95 & 27.65 & 0.673 & 1.52 \\
$(4)$ & -28.33 & 55.12 & 0.477 & 1.08 \\
$(5)$ & -17.13 & 29.09 & 0.656 & 1.48 \\
$(6)$ & 33.75 & 14.89 & 0.917 & 2.08 \\
$(7)$ & -11.25 & 34.91 & 0.599 & 1.36 \\
$(8)$ & 11.33 & 25.74 & 0.697 & 1.58 \\
$(9)$ & 11.34 & 26.57 & 0.686 & 1.56 \\
$(10)$ & -11.33 & 35.69 & 0.592 & 1.34 \\
$(11)$ & 34.19 & 15.78 & 0.891 & 2.02
\end{tabular}

\section{(1) A truss.}

A truss frame with rigid nodes shown in Fig.4 is analyzed: $E A=56,346$. tonf, $E I=$ 317,100 . tonf $\mathrm{cm}^{2}$, and yield stress $\sigma_{Y}=$ 2.4 tonf $/ \mathrm{cm}^{2}$. In a loading of vertical $P$ applied at node 1,2 and 3 , the global buckling is determined at 19.6 tonf. By the use of Eq.(24) for the buckling modes of members, the critical $N_{(m)}^{C}$ 


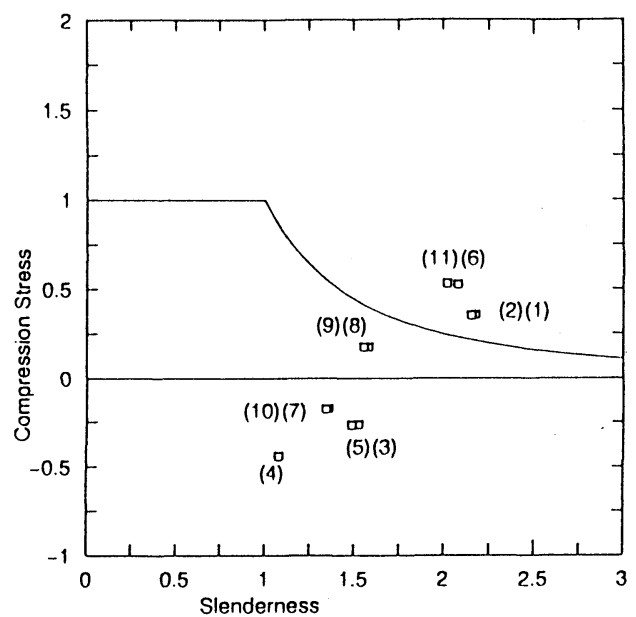

Fig. 5 Member state in displacement mode in Example ( 1 )

are estimated. Effective-length factor $K_{(m)}$ and slenderness parameter $\bar{\lambda}_{(m)}$ for those critical axial forces are given in Table 1 , together with the actual $N_{(m)}^{S}$. In this table, the numerical differences between each two members in the symmetry are due to the buckling determined after a slight excess into the bifurcation path. The stability states of members are plotted in Fig.5. Since the mode has no translations at the nodes, the critical $N_{(m)}^{D}$ are the same to $N_{(m)}^{C}$.

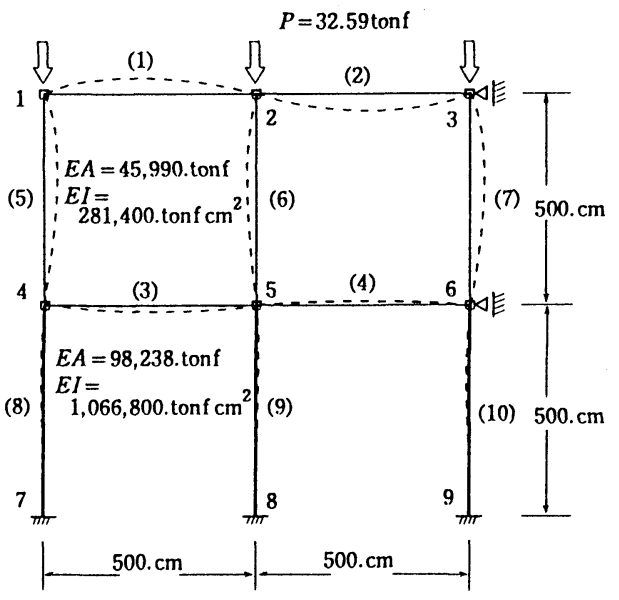

Fig. 6 Buckling mode in Example (2)

\section{(2) A braced rectangular frame}

We consider a braced frame consisting of two different cross-sections (see Fig.6): $E A=$ 45,990. tonf and $E I=281,400$. tonf $\mathrm{cm}^{2}$ for member (1) to (7); and $E A=98,238$. tonf and
Table 2 Actual axial force and critical quantities in Example ( 2)

\begin{tabular}{c|r|rcc} 
No. & \multicolumn{1}{|c|}{$N^{S}$} & $N^{C}$ & $K$ & $\bar{\lambda}$ \\
\hline$(1)$ & 0. & 12.12 & 0.957 & 2.08 \\
$(2)$ & 0. & 12.11 & 0.958 & 2.08 \\
$(3)$ & 0. & 12.17 & 0.955 & 2.08 \\
$(4)$ & 0. & 12.12 & 0.957 & 2.08 \\
$(5)$ & 32.59 & 17.06 & 0.807 & 1.76 \\
$(6)$ & 32.59 & 17.08 & 0.807 & 1.75 \\
$(7)$ & 32.59 & 17.08 & 0.807 & 1.75 \\
$(8)$ & 32.59 & 98.24 & 0.655 & 1.07 \\
$(9)$ & 32.59 & 98.37 & 0.654 & 1.07 \\
$(10)$ & 32.59 & 98.34 & 0.654 & 1.07
\end{tabular}

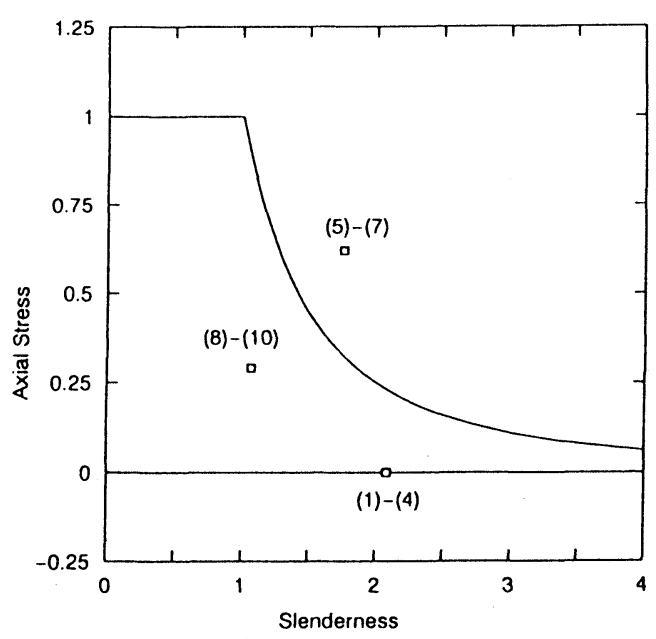

Fig. 7 Member state in Example (2)

$E I=1,066,800$. tonf $\mathrm{cm}^{2}$ for (8) to (10). The buckling load is obtained as $P=32.59$ tonf. The actual $N_{(m)}^{S}$, and the critical $N_{(m)}^{C}, K_{(m)}$ and $\bar{\lambda}_{(m)}$ are given in Table 2. The states of members are plotted in Fig. $7\left(\sigma_{Y}=2.4\right.$ tonf $\left./ \mathrm{cm}^{2}\right)$.

\section{(3) A rectangular frame with no brace}

In the three-storied framework shown in Fig.8, first, the same cross-section is assumed for all the members: $E=2,100$. tonf $/ \mathrm{cm}^{2}, A=21.9 \mathrm{~cm}^{2}$, $I=134 . \mathrm{cm}^{4}$, and $\sigma_{Y}=2.4$ tonf $/ \mathrm{cm}^{2}$. In a loading of vertical $P$ at node 1, 2 and 3, the buckling is determined at 5.70 tonf. As shown in Fig.9, all the compressed column members are instable in the displacement modes. On the other hand, Figure 10 shows that they are stable in their deformation modes. 


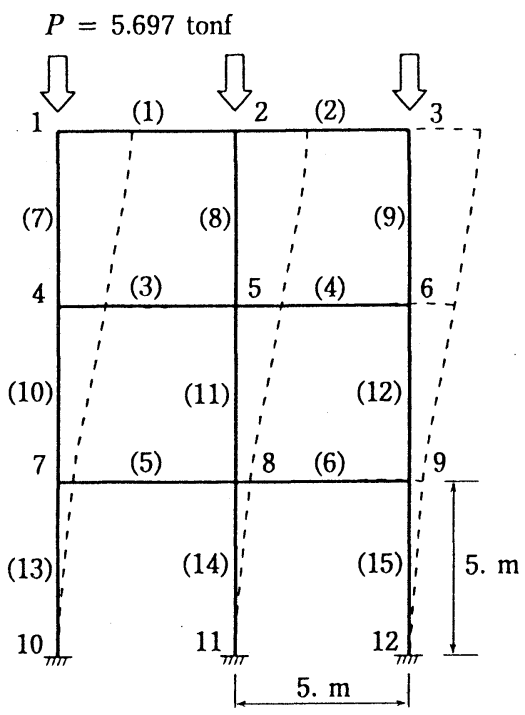

Fig. 8 Buckling mode in Example ( 3 )

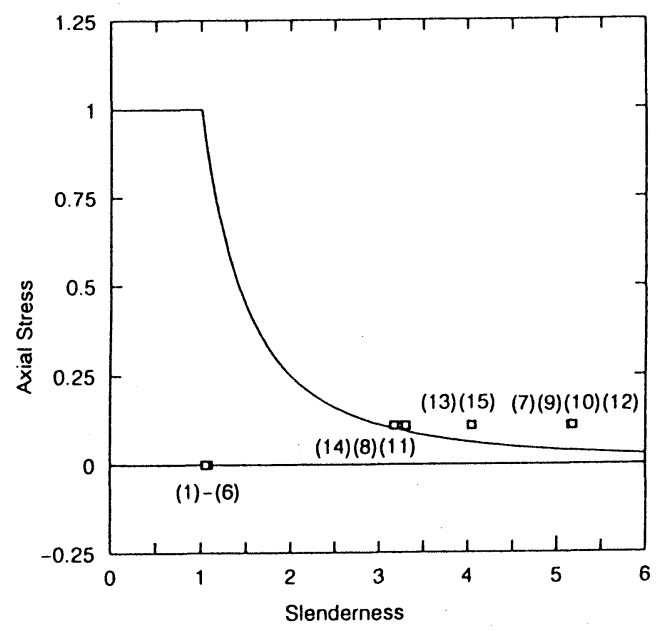

Fig. 9 Member state in displacement mode

Figure 11 shows the buckling for $P$ applied at node 2 only. The actual $N_{(m)}^{S}$ and the critical quantities are obtained as given in Table 3 . The stability states of members in the displacement mode are shown in Fig.12: only member (8), (11) and (14) are lying in the instable domain.

Next, member (5), (10) and (13) are replaced by a smaller cross-section: $A^{\prime}=11.85 \mathrm{~cm}^{2}$ and $I^{\prime}=14.8 \mathrm{~cm}^{4}$. The buckling in the vertical loading at node 1,2 and 3 is at $P=3.79$ tonf (Fig.13). Even in their deformation modes, as shown in Fig.14, member (10) and (13) remain in the instable domain.

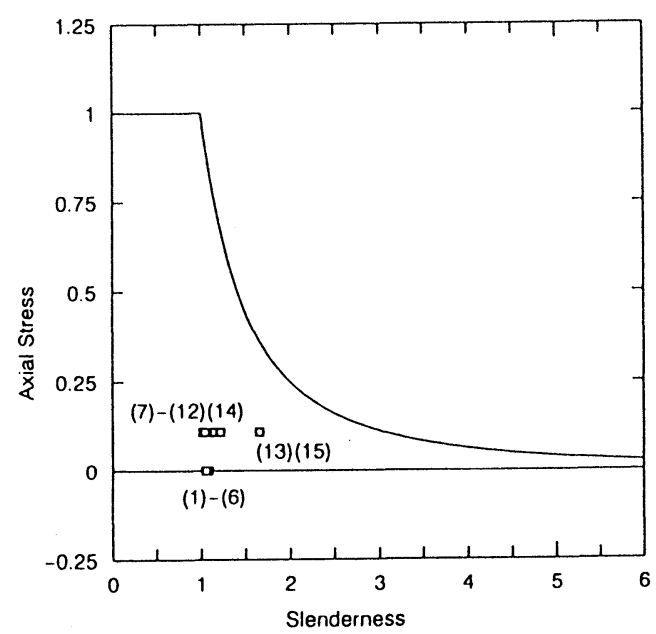

Fig. 10 Member state in deformation mode

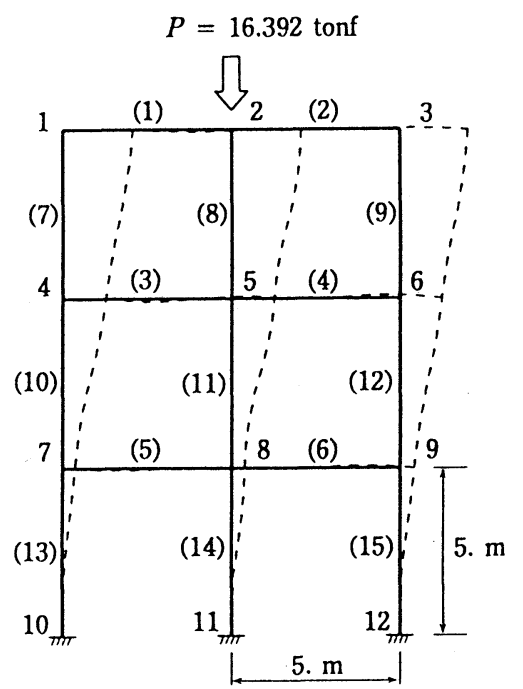

Fig. 11 Buckling mode in loading at node 2

\section{CONCLUDING REMARKS}

In the method of Ref.[2], any compressed members in a global buckling are regarded as critical all together at their actual axial forces, $N_{(m)}^{S}$. In Example ( 2 ), if the effective lengths are estimated for those $N_{(m)}^{S}$, we have $l_{\text {eff.(5)-(7) }}^{S}=$ $291.9 \mathrm{~cm}<l_{\text {eff. }(8)-(10)}^{S}=568.4 \mathrm{~cm}$. This result is contrary to the followings: since member (8) to (10) have a bending rigidity four times larger than other column members, as well as clamped at their lower ends, they shall have larger buckling strengths than member (5) to (7). In Example ( 3 ), a numerical result has been given for a vertical $P$ applied at node 2 only. Even in 
Table 3 Actual axial force and critical quantities with $P$ at node 2

\begin{tabular}{c|r|rrr} 
No. & \multicolumn{1}{|c|}{$N^{S}$} & \multicolumn{1}{|c}{$N^{C}$} & $K$ & $\bar{\lambda}$ \\
\hline$(1)(2)$ & 0.00 & 33.90 & 0.572 & 1.245 \\
$(3)(4)$ & 0.00 & 45.68 & 0.493 & 1.073 \\
$(5)(6)$ & 0.00 & 43.52 & 0.505 & 1.099 \\
$(7)(9)$ & 0.01 & 1.63 & 2.612 & 5.681 \\
$(8)$ & 16.37 & 6.42 & 1.315 & 2.860 \\
$(10)(12)$ & 0.02 & 1.78 & 2.497 & 5.432 \\
$(11)$ & 16.36 & 5.54 & 1.417 & 3.081 \\
$(13)(15)$ & 0.02 & 3.10 & 1.892 & 4.115 \\
$(14)$ & 13.74 & 6.10 & 1.349 & 2.935
\end{tabular}

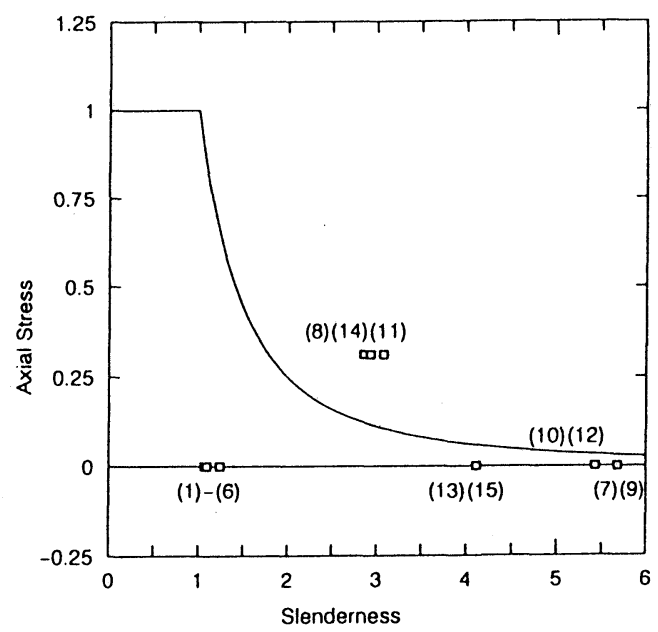

Fig. 12 Member state in displacement mode

case a very small fraction of $P$ are added at node 1 and 3 , we have almost the same result. In this case, the aforesaid method might give any large effective-lengths to the side column members. On the other hand, the effective lengths evaluated in this study from the critical $N_{(m)}^{C}$ are much acceptable for the changes of cross-section (Table 2), and are consistent for any states of members: tensioned or compressed (Table 3 and Fig.12).

The load carrying capacity of a structure can be decisively affected by the local buckling. In the design analysis, there has been the terminology local buckling, such as for the buckling into the distortion of cross-section. But, in the computation analysis of a discretized model, we do not have an explicit definition for the local buckling. In the buckling of a framed structure, for instance, the instable rotation as a rigid body of

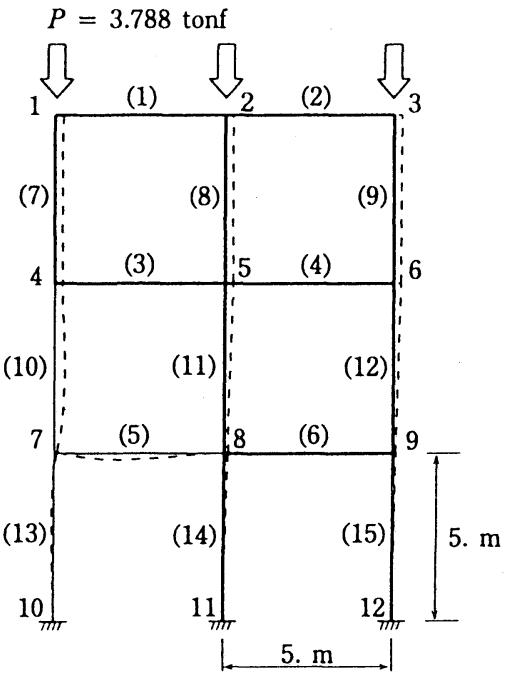

Fig. 13 Buckling mode with a small cross-section of member (5), (10) and (13)

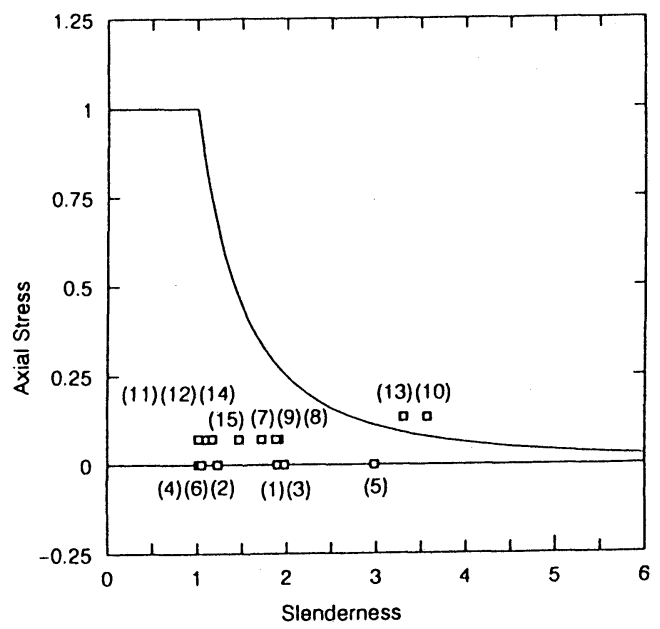

Fig. 14 Member state in deformation mode

a compressed member is balanced with the stable deformations of other members. In the global buckling, which is observed in the space-fixed coordinates, the stable and instable members are interactive. On the other hand, the instability of a member in its deformation mode $\boldsymbol{E}_{(m)}^{S}$ is a phenomenon in itself, measured in a local coordinate system which goes with its displacement as a rigid body. The treatment in Sec.5. can leads to a basic definition of the local buckling.

In Eq.(6) ( Eq.(16)), the critical $N_{(m)}^{C}\left(N_{(m)}^{D}\right)$ is determined proportionally to the magnitude of bending rigidity $E I$. Then, in Eq.(8), which con- 
tains denominator $N_{(m)}^{C}$ and numerator $E I$, the resulting effective length $l_{\text {eff. }(m)}^{C}\left(l_{\text {eff. }(m)}^{D}\right)$ is not affected by the dimension of $E I$, in principle. The effective length is dependent only on displacement mode $\left\{\boldsymbol{X}^{S}\right\}_{(m)}$ (deformation mode $\boldsymbol{E}_{(m)}^{S}$ ). This is the same with the Euler bucklings with various boundary conditions.

\section{APPENDIX A. NOTATIONS}

$$
\begin{aligned}
& \left\{P_{N}^{*}\right\}=\text { loading mode; } \\
& \rho=\text { load factor; } \\
& {\left[K_{O N}\right],\left[k_{O}\right]_{(m)}=\text { initial stiffness matrix (global/ }} \\
& \text { member); } \\
& {\left[K_{G N}\right],\left[k_{G}\right]_{(m)}=\text { geometrical stiffness matrix }} \\
& \text { (global/member); } \\
& \left\{X_{N}^{S}\right\},\left\{X^{S}\right\}_{(m)}=\text { buckling mode (global/member); } \\
& \Gamma, I_{(m)}=\text { quadratic work of tangent } \\
& \text { stiffness (global/member); } \\
& N_{(m)}^{S}=\text { member actual axial force in } \\
& \text { a global buckling; } \\
& N_{(m)}^{C}, N_{(m)}^{D}=\text { member critical axial forces } \\
& \text { in displacement and defor- } \\
& \text { mation modes, respectively; } \\
& l_{\text {eff. }(m)}^{S}=\text { effective length for } N_{(m)}^{S} ; \\
& l_{\text {eff. }(m)}^{C}, l_{\text {eff. }(m)}^{D}=\text { effective lengths for } N_{(m)}^{C} \\
& \text { and } N_{(m)}^{D} \text {, respectively; } \\
& ()^{*},\left(^{-}\right)=\text {derivatives with respect to } \rho \\
& \text { and } N \text {, respectively; } \\
& E=\text { Young's modulus; } \\
& A=\text { cross-section area; } \\
& I=\text { moment of inertia of cross- } \\
& \text { section; } \\
& l=\text { initial member length; } \\
& \{\boldsymbol{u}\}_{(m)},\{\boldsymbol{F}\}_{(m)}=\text { member nodal displacements }
\end{aligned}
$$

$$
\epsilon_{(m)}, f_{(m)}=\begin{aligned}
& \text { member deformation and de- } \\
& \text { formation force, respectively }
\end{aligned}
$$

\section{REFERENCES}

1) Japan Road Association: Specifications for highway bridges, Part II, Steel Bridges, Maruzen, Feb. 1990 (in Japanese).

2) Nishino, F., Miki, C. and Suzuki, A: Background of revision of specifications for highway bridges (Japan road association) - design of rigid frames, Bridge and Foundation Engineering, Vol.15, No.10, pp.1013, 1981-10 (in Japanese).

3) Kuranishi, S. (ed.): Ultimate strength and design of steel structures, JSCE, pp.130-133, 1994 (in Japanese).

4) Nogami, K.: On the practical procedure of effective buckling length of framed columns, Journal of Structural Engineering, JSCE, Vol.39A, pp.199-209, 19933 (in Japanese).

5) Nishino, F. and Attia, W.: A proposal for in-plane stability design of steel framed structures, Structural Eng./Earthquake Eng., Vol.8, No.4, pp.169s-178s, Jan., 1992.

6) Kurakata, Y., Nishino, F. and Hasegawa, A: Some problems on the current stability design rules for steel framed structures (1)/(2), Bridge and Foundation Engineering, Vol.26, No.2, pp.19-27, 1992-2 / Vol.26, No.3, pp.41-46, 1992-3 (in Japanese).

7) Nogami, K. and Yamamoto, K.: On the effective buckling length of framed columns using eigenvalue analysis J. Struct. Mech. Earthquake Eng., JSCE, No.489/I-27, pp.157-166, 1994-4 (in Japanese).

8) Ai, M. and Nishino, F.: Mechanics in geometrically nonlinear problem of discrete system and application to plane frame-works, Proceedings of JSCE, No.304, pp.17-32, 1980-12 (in Japanese).

9) Nakano, T., Ai, M. and Nishino, F.: An estimation of the effective buckling length of frame members, Proc. of the Annual Conference, JSCE, Vol.I(A), pp.60-61, 1996 (in Japanese).

(Received August 9, 1996)

\title{
骨組構造の全体座屈時における部材の安定性について
}

\author{
西野 文雄・阿井 正博・中野 智文
}

全体座屈において，座屈モ一ドに対する全体接線岡性の 2 次形式は零値となるが，その節点変位 に対する各部材自身の接線剛性の 2 次形式は正, 負の值をもつのが普通であり，零値になるとは限ら ない. 全体座屈とは、混在した安定部材と不安定部材がバランスした状態といえる. このとき, 全 体モードよりきまる部材変位がそれぞれの部材の限界状態 ( 2 次形式の零值) となる軸力を, 全体座 屈時の軸力とは別に考えることができる. 部材有効長はこの限界軸力に対して定義されるべき量と 考えられ, Euler-座屈曲線に対する\{限界軸力での有効長, 全体座屈時の実際の軸力\}の位置により, 部材の安定状態を明示することができる. 